\title{
P04.82. Yoga for breast cancer: a systematic review of randomized controlled trials
}

\author{
H Cramer ${ }^{*}$, S Lange, P Klose, A Paul, G Dobos \\ From International Research Congress on Integrative Medicine and Health 2012 \\ Portland, Oregon, USA. 15-18 May 2012
}

\section{Purpose}

To systematically review the effectiveness of yoga in patients with breast cancer.

\section{Methods}

MEDLINE, PsychInfo, EMBASE, CAMBASE, and the Cochrane Library were screened through September 2011. Randomized controlled trials (RCTs) comparing yoga to controls were analyzed. Risk of bias was assessed using the Cochrane risk of bias tool. For each outcome, standardized mean differences (SMD) and 95\% confidence intervals $(\mathrm{CI})$ were calculated, if it at least 2 studies assessing this outcome were available. As a measure of heterogeneity, $\mathrm{I}<\sup >2</$ sup $>$ was calculated.

\section{Results}

11 RCTs and 655 subjects were included. 7 RCTs compared yoga to wait-list control groups, 3 RCTs compared yoga to supportive therapy and 1 RCT compared a combination of physiotherapy and yoga to physiotherapy alone.

Yoga compared to control showed significantly greater improvements in global health-related quality of life (HRQoL) (SMD $=0.62$, [95\% CI 0.04, 1.21] $\mathrm{p}=0.04$, $\mathrm{I}^{2}=79 \%$ ), as well as in functional (SMD $=0.30[95 \% \mathrm{CI}$ $\left.0.03,0.57], \mathrm{p}=0.03, \mathrm{I}^{2}=0 \%\right)$, social $(\mathrm{SMD}=0.29[95 \% \mathrm{CI}$ $\left.0.08,0.50], \mathrm{p}=0.006, \mathrm{I}^{2}=0 \%\right)$, and spiritual HRQoL $\left(\mathrm{SMD}=0.41[95 \% \mathrm{CI} 0.08,0.74], \mathrm{p}=0.01, \mathrm{I}^{2}=0 \%\right)$. Greater improvements were also found in anxiety $(\mathrm{SMD}=-1.51$ [95\% CI -2.47, -0.55], $\left.\mathrm{p}=0.002, \mathrm{I}^{2}=94 \%\right)$, depression $(\mathrm{SMD}=-1.83$ [95\% CI $\left.-3.13,-0.53], \mathrm{p}=0.006, \mathrm{I}^{2}=95 \%\right)$, perceived stress $(\mathrm{SMD}=-2.13$ [95\% CI $-3.48,-0.78]$, $\left.\mathrm{p}=0.002, \mathrm{I}^{2}=91 \%\right)$, psychological distress $(\mathrm{SMD}=-1.10$ [95\% CI $-1.77,-0.43], \mathrm{p}=0.001, \mathrm{I}^{2}=85 \%$ ), and fatigue $(\mathrm{SMD}=-0.33$ [95\% CI -0.65 to -0.01$\left.], \mathrm{p}=0.04, \mathrm{I}^{2}=49 \%\right)$.

\footnotetext{
University of Duisburg, Complementary and Integrative Medicine, Essen,
} Germany

C 2012 Cramer et al; licensee BioMed Central Ltd. This is an Open Access article distributed under the terms of the Creative Commons Attribution License (http://creativecommons.org/licenses/by/2.0), which permits unrestricted use, distribution, and reproduction in any medium, provided the original work is properly cited.
No significant group differences were found in physical, emotional and mental HRQoL, breast cancer specific concerns and sleep disturbances.

\section{Conclusion}

There is encouraging evidence that yoga has beneficial effects on HRQoL, psychological health and fatigue in breast cancer patients. Due to methodological and statistical heterogeneity, larger studies with rigorous trial design and reporting are necessary to underpin these results.

Published: 12 June 2012

doi:10.1186/1472-6882-12-S1-P352

Cite this article as: Cramer et al:: P04.82. Yoga for breast cancer: a systematic review of randomized controlled trials. BMC Complementary and Alternative Medicine 2012 12(Suppl 1):P352. and take full advantage of:

- Convenient online submission

- Thorough peer review

- No space constraints or color figure charges

- Immediate publication on acceptance

- Inclusion in PubMed, CAS, Scopus and Google Scholar

- Research which is freely available for redistribution 